\title{
Some Experiments on the Drug Treatment of Trypanosomiasis.
}

\author{
By W. H. Andrews, B.Se, M.R.C.V.S.
}

These experiments were commenced in the year 1910 by Dr. H. Sieber, and were continued in 1911 by W. H. Andrews.

During 1912 further experiments in " combined treatment" have been undertaken by W. H. Andrews in collaboration with Dr. Wölfel, of German East Africa, and Mr. van Raes, of the Belgian Congo.

Species of the Trypanosome concerned.-In all cases the trypanosomes concerned were of the T.congolense type (or T.pecorum of Bruce), but in the earlier experiments a number of different strains were used, including one obtained from Hartley, S. Rhodesia, and several strains from different localities in Portuguese East Africa.

The later experiments all refer to the "Guara-Guara" strain sent from Portuguese East Africa in May, 1910, by Mr. W. Jowett, and described by him in the Journal of Comparative Pathology and Therapeutics for September, 1910.

With regard to Jowett's description, it may be remarked that the strain in the Onderstepoort laboratory was obtained from an inoculated guinea pig, and that only the small form, without a free flagellum, was observed.

In August, 1911, the original strain was lost, and had to be recovered from a heifer when dying from a relapse after treatment with Arsenophenylglycin.

In subsequent experiments the strain used was, therefore, one which had been resistant to arsenophenylglycin in one passage.

It may be mentioned that in recent outbreaks of trypanosomiasis in Zululand and N'gamiland (Bechuanaland Protectorate) the trypanosomes have also been of the T.congolense type, and indistinguishable morphologically one from the other, and from the strains above-mentioned.

Virulence of the Trypanosomes.-No significant differences with regard to the lethality for the various species of domesticated animals, and to the duration of infection and incubative period, were noted in the several strains of trypanosomes utilised.

Horses and mules were largely used in the earlier experiments, and in them the trypanosomes were generally first seen in the peripheral blood about 21 days after inoculation, the period varying between 15 and 30 days; in one case they were not recorded until the forty-first day. 
A small number of these horses and mules, which were subjected to treatment varying in the different cases, died from 2 to 5 months after inoculation, and in a considerable number of cases the animals were killed, after the lapse of several months, on account of emaciation and debility, but this debilitated condition could not in all cases be attributed entirely to the trypanosome infection.

On the other hand, some animals appeared to be surviving for very long periods without showing any signs of serious ill-health, and in this connection the case of one animal (Mule 5,338) may be quoted

The mule was injected with the Guara-Guara strain (from a sheep) on the 25th January, 1911, and trypanosomes were found in the peripheral blood on the 9th February, the 15th day.

The mule was not treated, but was kept as a control animal.

On the 12th August, nearly 7 months after infection, the animal was in rather poor condition, although otherwise appearing to be in good health, but inoculation of two sheep, each with 20 c.c. of blood, gave positive evidence of trypanosome infection; the mule was killed three weeks later on account of limitations of space, all infected animals being kept in fly-proof stables.

It would thus appear that the infection tends to run a very slow course in equines, although the majority of infected animals would ultimately succumb from anaemia. For this reason the later experiments were made with sheep.

Only two experiments were made with cattle, and in these the trypanosomes appeared in the blood 11 and 12 days respectively after inoculation. Both animals were treated unsuccessfully with arsenophenylglycin, and death occured in 43 and 95 days respectively.

ithe strain (Guara-Guara) is apparently considerably more virulent for cattle than for horses and mules.

A very considerable number of sheep were under observation, as, in addition to those used in experiments on specific methods of treatment, there were those used to keep up the strains, the sheep being generally used by us for this purpose.

In sheep, the trypanosomes appeared in the peripheral blood between 4 and 18 days (in one case 34 days) after inoculation, the average period being 5-6 days.

The duration of the disease varied within very wide limits; rather less than $50 \%$ of infected sheep died within one month of inoculation, the period exceptionally being as short as 7 days.

In the other cases, the sheep survived for months, and, in about $10 \%$ of cases, even for a year.

A number of dogs were injected with the blood of infected animals, with the object, in most cases, of observing the effect of some previous treatment on the latter.

In those dogs which became infected, the trypanosomes appeared in the peripheral blood in $9-17$ days, and the animal died from 15 to 36 days after inoculation. 
In one case, however, a dog, injected with the blood of a mule which had undergone drug treatment, showed trypanosomes only after a lapse of 31 days, and it survived for 51 days, when it was killed by other dogs in the same kennel.

The results of inoculations from Mule 5,338 (a control animal, infected with the Guara-Guara strain) are curious. A dog injected on the 139th day of the infection with 100 c.c. of the mule's blood, did not contract the infection, whereas two sheep injected 60 days later with 20 c.c. and 40 c.c. respectively of the blood, died from trypanosomiasis in 36 and 50 days respectively (comp. Mule 5,145, treated with arsenophenylglycin, and Mule 5,174, treated with Novoflavin).

The problem of the drug treatment of trypanosomiasis in domesticated animals differs from that of the treatment of Sleeping Sickness in man, in that the attention which may practicably be paid to individual cases is necessarily much more limited in the former case.

A method of treatment, if it is to be of any practical importance in such a country as Rhodesia or Moçambique, must involve the performance of only very few and simple operations, in order that it may be applied to a large number of patients within a reasonably short period, and that the assistance and equipment required may be cut down to a minimum.

We were, therefore, concerned chiefly with the effects of only a small number of injections, and treatment was sometimes abandoned in cases which might possibly have recovered, had the treatment been continued for longer periods.

On the other hand, it was recognised that the desired results could not be expected from any one trypanocidal agent at present known, and that a combination of two or more drugs was essential.

In practically all cases the agents were injected, in dilute solution, into the jugular vein.

Before giving the results of experiments with several combinations of drugs, the following observations on the trypanocidal actions of certain individual agents may be recorded. 
Table I.-Treatment with Arsenophenylglycin.

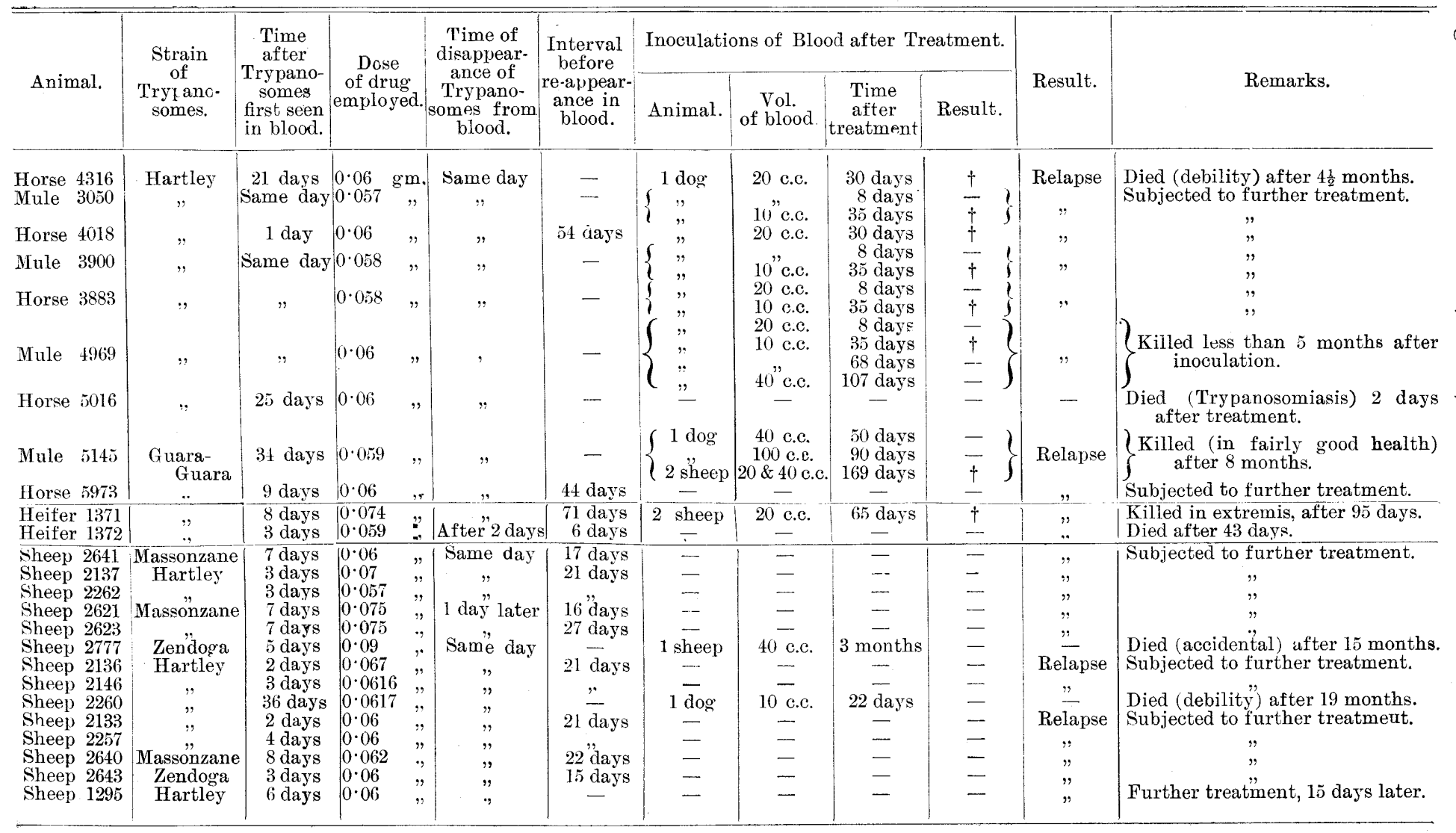


It will be seen that 9 infected horses and mules were injected with doses of arsenophenylglycin varying from 0.057 to $0.06 \mathrm{grm}$. per kilogramme of body weight, and that relapse followed in every case, but that of a horse which died two days after the injection was made. Trypanosomes were actually seen in the peripheral blood, after treatment, only in two instances, but in the other cases their presence was demonstrated by sub-inoculations into sheep or dogs, such inoculations usually giving positive results $30-35$ days after the treatment.

It must also be mentioned that in Mule 5,338, kept as a control animal, microscopic examination of the blood frequently gave negative results (and, on two occasions, inoculation of dogs).

Ehrlich and his collaborators have fixed the maximal therapeutic dose of arsenophenylglycin for the horse at 0.05 gramme per kilogramme of body weight. (Bulletin de l'Institut Pasteur, April, 1909.)

It is, therefore, evident that the above doses, all of which proved to be insufficient, could not with safety be increased.

Two cases deserve special attention; in the first place it should be noted that Mule 4,969 gave a positive result with a subinoculation of blood taken from the mule 35 days after treatment, but that similar inoculations, on the 68 th and $10 \%$ th days respectively, proved negative.

Secondly, Mule 5145 gave negative results with sub-inoculations into dogs performed on the 50th and 90th days after treatment, although in the latter case 100 c.c. of blood was injected; yet 79 days later 20 e.c. of blood was infective to sheep.

In both cattle relapse followed treatment; the dose of $0.059 \mathrm{gm}$. per kilogramme, given in one case, was obviously insufficient, as the trypanosomes disappeared but slowly from the peripheral blood, while in the other case a dose of $0.074 \mathrm{gm}$. was well supported, and gave a more promising result. We were not able to make further experiments with cattle, although such are perhaps very desirable, in that the losses in Moçambique are apparently most serious in bovines.

The maximal therapeutic dose of arsenophenylglycin for cattle should be determined more exactly.

Of the sheep, eleven animals were treated with a single dose of arsenophenylglycin, varying in different cases from 0.057 to $0.075 \mathrm{gm}$. per kilogramme of body weight; in each case there was a relapse, the trypanosomes in all cases reappearing in the peripheral blood, and generally about 21 days after treatment (limits $15-27$ days).

One sheep (S. 1295) was given a dose of $0.06 \mathrm{gm}$. per kilo., and no relapse had occurred up to the 15th day, on which day further treatment was instituted.

Two other sheep, which received doses of 0.09 and $0.0617 \mathrm{gms}$. respectively, appear to have been cured thereby; trypanosomes were never recorded in the peripheral blood, subsequent to treatment, and in each case a sub-inoculation gave a negative result.

The favourable result obtained with Sheep $277 \%$ might be ascribed to the size of the dose $(0.09 \mathrm{gm}$.) of arsenophenylglycin employed, but this will not explain the case of Sheep 2260, in which a dose of only $0.0617 \mathrm{gm}$. was given. 
In this connection it is of interest to note that in the case of Sheep 2621, in which the results are the least favourable of those obtained with sheep, a dose of $0.075 \mathrm{gm}$. was employed.

With regard to the stage of the infection at the time treatment was undertaken, it will be seen that in different cases the injection was given from a few hours to 36 days after trypanosomes were first seen in the peripheral circulation, but that the results were not clearly affected by this factor.

\section{NOVOFLAVIN.-See Table II.}

Six equines received each a dose of 0.01 gramme, and one mule was given 0.0098 gramme per kilogramme body weight.

In three cases the animal treated was suffering from a relapse after treatment with arsenophenylglycin, and in these cases the trypansomes disappeared from the peripheral blood and were not found again, the animals being killed on account of general debility about two months after the injection of Novoflavin was given.

In one of the four cases in which Novoflavin was given to animals otherwise not treated, the animal was shown to be infected by subinoculation of blood into sheep, on the 169th day after treatment.

This animal (the mule which received only $0.0098 \mathrm{gm}$. ) was killed six and a half months after treatment, although the general health was fairly good.

In the other three cases the animals had to be killed on account of general debility; this was done 11 days after the treatment in one case, and after 25 days in the other cases, and no relapse was observed.

Eleven sheep were injected with a dose of from 0.009 to 0.013 gramme of Novoflavin per kilogramme, and in three cases the drug produced a fatal intoxication; in two other instances the sheep died, 12 and 15 days respectively after treatment, from an accidental complication, pneumonia.

In the remaining six cases, all of which had previously been treated unsuccessfully with arsenophylglycin, or with salvarsan, relapses occurred, trypanosomes reappearing in the blood 13 to 29 days after treatment.

In view of the fact that on several occasions a dose of $0.01 \mathrm{gm}$. per kilo. proved fatal, and that on two occasions a fatal intoxication was produced by a dose of $0.013 \mathrm{gm}$., it is evident that in the sheep the doses given approximated closely to the maximal therapeutic dose, and that they could not with safety be increased.

With equines also a dose of 0.01 per kilo. on two occasions (out of 10) proved fatal, although a larger dose was given in two cases, without producing any serious effects. The dose of $0.01 \mathrm{gm}$. is therefore considered as the maximum dose for equines.

Novoflavin is, therefore, to be classed, with several similar drugs, as a useful trypanocidal agent, which, however, in the majority of cases, will fail completely to sterilise. 


\section{Table II.-Treatment with Novoflavin.}

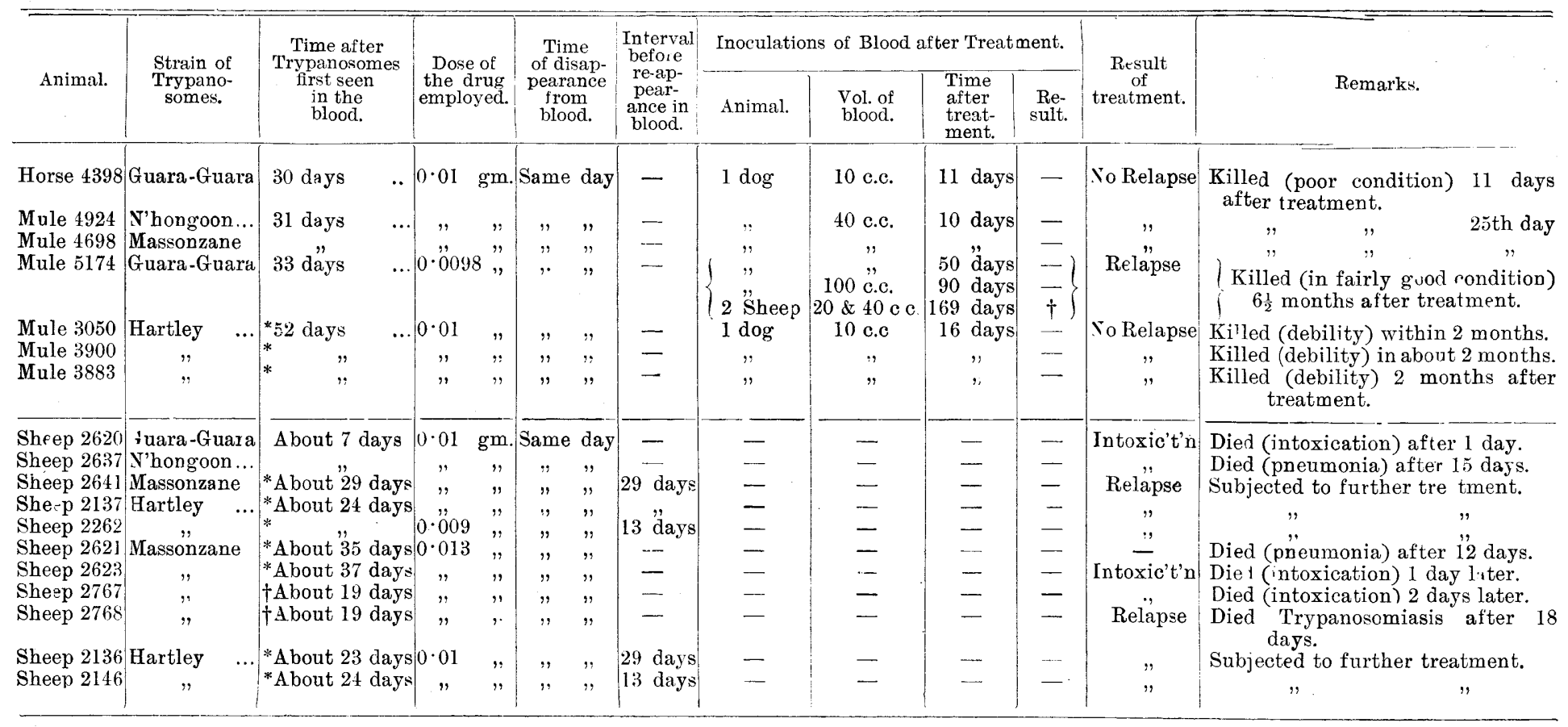

* Signifies that the animal was first injected with arsenophenylglycin, and had showr signs of a relapse.

$\dagger$ Signifies that the animal was first treated unsuccessfully with Salvarsan. 


\section{SALVARSAN, or "606."}

In the accompanying table (Table III.) it will be seen that this drug was administered to 15 sheep infected with Trypanosomiasis.

In the first three cases the animals received Salvarson after unsuccessful treatment with arsenophenylglycin and novoflavin, and the drug was injected into the jugular vein as a $1 \%$ solution in normal saline.

In the remaining cases Salvarsan was injected at an early stage of the infection, these results being therefore free from any sources of error connected with the treatment with other agents; the strain used, however, had been recovered from an animal dying after unsuccessful treatment with arsenophenylglycin, and had subsequently been passed through 5 sheep, untreated. In these later cases, the drug was given, intravenously, as a 1-500 neutral solution.

In order to determine the maximum therapeutic dose, ten normal sheep were injected intravenously with varying doses of Salvarsan (in 1-500 neutral solution) with the following results:-

2 sheep received $0.02 \mathrm{gm}$. of " 606 ", per kilo-no effect.

2 sheep received $0.03 \mathrm{gm}$. of " 606 " " per kilo-some salivation.

2 sheep received $0.04 \mathrm{gm}$. of " 606 " per kilo-some salivation.

2 sheep received $0.05 \mathrm{gm}$. of " 606 ", per kilo-both sheep died.

2 sheep received $0.06 \mathrm{gm}$. of " 606 " per kilo-both sheep died.

The maximum dose was therefore fixed at $0.04 \mathrm{gm}$. per kilo.

The results of treatment were not at all encouraging, although in five cases the dose given was actually that determined as the maximum.

In practically all cases, after the injection of large doses of Salvarsan, the trypanosomes in the peripheral circulation diminished in number for from two to five days, but they never actually disappeared, and a few days later they increased very rapidly.

It is therefore apparent that, at least as far as concerns sheep infected with this particular strain of trypanosome, Salvarsan has only a very feeble trypanocidal action.

\section{COMBINATIONS OF TRYPANOCIDAL AGENTS.}

\section{ARSENOPHENYLGLYCIN AND NOVOFLAVIN.}

(a) One injection of each agent given in succession. See Table IV.

Of the four equines subjected to this treatment, three received the injection of Novoflavin after an interval of 52 days, when a relapse after Arsenophenylglycin had already been demonstrated; in the fourth case the two injections were separated by an interval of only 9 days. 


\section{Table III.-Treatment with Salvarsan.}

\begin{tabular}{|c|c|c|c|c|c|c|}
\hline Animal. & $\begin{array}{c}\text { Strain of } \\
\text { trypanosomes. }\end{array}$ & $\begin{array}{l}\text { Time which had } \\
\text { elapsed since } \\
\text { trypanosimes } \\
\text { were first seen } \\
\text { in the blood. }\end{array}$ & $\begin{array}{l}\text { Dose of } \\
\text { Salvarsan } \\
\text { per kilo. }\end{array}$ & $\begin{array}{l}\text { Effect on the trypanosom } \\
\text { in the peripheral blood. }\end{array}$ & & Remarks. \\
\hline $\begin{array}{c}\text { Sheep : } \\
*+2641 \\
*+2136 \\
*+2137 \\
3773 \\
3766 \\
3757 \\
\\
3756 \\
3769 \\
3768 \\
3810 \\
3813 \\
3765 \\
3811 \\
3764 \\
\\
3775 \\
3812\end{array}$ & $\begin{array}{c}\text { Massonzane. } \\
\text { Hartley. } \\
\text { ". } \\
\text { Guara-Guara. } \\
\text { " } \\
\text { " } \\
\text {, } \\
" \\
" \\
" \\
" \\
" \\
" \\
"\end{array}$ & $\begin{array}{l}59 \text { days. } \\
53 \text { days. } \\
55 \text { days } \\
4 \text { days. } \\
3 \text { days. } \\
3 \text { days. } \\
4 \text { days. } \\
3 \text { days. } \\
4 \text { days. } \\
2 \text { days. } \\
3 \text { days. } \\
1 \text { day. } \\
1 \text { day. } \\
2 \text { days. } \\
\text { Control. }\end{array}$ & 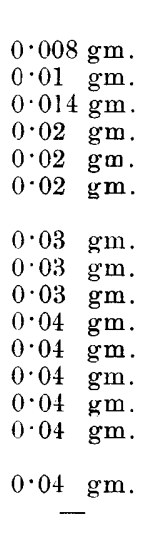 & $\begin{array}{ccc}\text { No effect } & \ldots & \ldots \\
" & \ldots & \ldots \\
" & \ldots & \ldots \\
", & \ldots & \ldots \\
\text { Fewer in number on second } \\
\text { numerous on third day. } \\
\text { Fewer in number for } 3 \text { days } \\
\text { No effect } \ldots \\
\text { Fewer in number for } 5 \text { days } \\
\text { " } \\
\text { Fexer in number for } 3 \text { days } \\
\text { No effect } \\
\text { Fewer in number for } 3 \text { days }\end{array}$ & $\begin{array}{l}\ldots \\
\ldots \\
\ldots \\
\ldots \\
\ldots \\
\text { day, } \\
\ldots \\
\ldots \\
\ldots \\
\ldots \\
\ldots \\
\ldots \\
\ldots\end{array}$ & $\begin{array}{l}\text { Subjected later to otber treatment. } \\
\qquad ", " \\
\text { ", " } \\
\text { Died (trypanosomiasis and pericarditis) in } \\
12 \text { days. } \\
\text { Died (trypanosomiasis) in } 76 \text { days. } \\
\text { Died (trypanosomiasis) in } 12 \text { days. } \\
\text { Subjected later to other treatment. } \\
\quad " \\
\quad " \\
\text { Dird (trypanosomiasis) in } 21 \text { days. } \\
\text { Died (trypanosomiasis and heartwater (?)) } \\
\text { in 30 days. } \\
\text { Subjected later to other treatment. } \\
\text { Died (trypanosomia-is) a ter } 77 \text { days. }\end{array}$ \\
\hline
\end{tabular}

* Previonsly treated unsuccessfully with arsenophenylglycin.

$\dagger$ Previously treated unsuccessfully with novoflavin. 
In no case were trypanosomes again seen in the blood, and inoculations into dogs on the 16th day (and in one case also on the 55th day) gave negative results, but all 4 animals were destroyed, about two months after the second injection, on account of general debility and emaciation.

It would appear that in these cases the debility was due, in large measure, to causes other than the trypanosome infection, and the animals were old and in poor condition at the commencement of the experiment.

Of the fourteen sheep, two died within a day from intoxication with Novoflavin, and two succumbed to accidental complications, and one sheep died from the effects of the previous infection (and treatment possibly, in part), before a relapse could be expected.

In two cases, where the injections were made on two successive days, no signs of relapse were detected, and the sheep died from accidental causes, nine and fourteen months respectively after the treatment was concluded.

All the remaining seven sheep showed relapses, the trypanosomes reappearing in the blood from 13 to 29 days after the second injection.

The treatment may therefore be considered to be worthy of more extended trial, but the debilitating effects of both infection and treatment should be counteracted, as far as possible, by commencing treatment early, and by giving the two injections at a reasonably short interval, before any relapse has oceurred. 
Table IV.-Combined Treatment with Arsenophenylgiycin and Novoflavin-Two Successive Doses.

\begin{tabular}{|c|c|c|c|c|c|c|c|c|c|c|c|}
\hline \multirow{2}{*}{ Animal. } & \multirow{2}{*}{\begin{tabular}{|l|} 
Interval \\
betwe en \\
appear- \\
ance of \\
trypano- \\
somes in \\
blood and \\
treatment.
\end{tabular}} & \multirow{2}{*}{$\begin{array}{c}\text { Dose of } \\
\text { Arsenophenyl- } \\
\text { glycin per } \\
\text { kilo. body } \\
\text { weight. }\end{array}$} & \multirow{2}{*}{$\begin{array}{c}\text { Interval } \\
\text { before } \\
\text { relapse } \\
\text { was } \\
\text { detected. }\end{array}$} & \multirow{2}{*}{$\begin{array}{c}\text { Interval } \\
\text { between } \\
\text { the two } \\
\text { injections. }\end{array}$} & \multirow{2}{*}{$\begin{array}{l}\text { Dose of } \\
\text { Novoflavin } \\
\text { per kilo. }\end{array}$} & \multirow{2}{*}{$\begin{array}{l}\text { Interval } \\
\text { before } \\
\text { trypano- } \\
\text { somes re- } \\
\text { appeared } \\
\text { in the } \\
\text { blood. }\end{array}$} & \multicolumn{4}{|c|}{$\begin{array}{l}\text { Inoculations made subsequent to } \\
\text { the second injection. }\end{array}$} & \multirow{2}{*}{ Remarks, } \\
\hline & & & & & & & Animal. & $\begin{array}{l}\text { Vol. } \\
\text { blood. }\end{array}$ & $\begin{array}{c}\text { afme } \\
\text { after } \\
\text { treatment. }\end{array}$ & Result. & \\
\hline Horse 3883 & 21 days & $0.058 \mathrm{gm}$ & 35 days & $\tilde{5} 2$ days & $0.01 \mathrm{gm}$. & - & $1 \mathrm{dog}$ & 10 c.c. & $\therefore 6$ days & - & $\begin{array}{l}\text { Killed (debility) } 2 \text { months after } \\
\text { treatment. }\end{array}$ \\
\hline Mule 3050 & 0 day & $0.057 \mathrm{gm}$. & 35 days & 52 days & $0.01 \mathrm{gm}$. & 一 & $1 \mathrm{~d} g$ & 10 c.c. & 16 days & - & $\begin{array}{l}\text { Killed (d.bility) within } 2 \text { months } \\
\text { after treatment. }\end{array}$ \\
\hline Mule 3900 & 0 day & $0.058 \mathrm{gm}$. & 35 days & 52 days & $0.01 \mathrm{gm}$. & - & $1 \mathrm{dog}$ & 10 c.c. & 16 days & - & $\begin{array}{l}\text { Killed (debility) about } 2 \text { months } \\
\text { after treatment. }\end{array}$ \\
\hline Mule 3509 & 40 days & $0.06 \mathrm{gm}$. & - & 9 days & $0.01 \mathrm{gm}$ & - & 2 dogs & $\left\{\begin{array}{l}110 \text { and } \\
\text { in c.c. }\end{array}\right.$ & $\left\{\begin{array}{l}16 \text { and } \\
5 \check{\text { days }}\end{array}\right.$ & - & $\begin{array}{l}\text { Killed (debility) about } 70 \text { days after } \\
\text { treatment. }\end{array}$ \\
\hline Sheep 2621 & 7 days & $0.075 \mathrm{gm}$. & 16 d:ys & 28 days & $0 \cdot 013 \mathrm{gm}$ & - & - & 一 & -- & 一 & $\begin{array}{l}\text { Died (Pneumon'a) } 13 \text { days after } \\
\text { treatment. }\end{array}$ \\
\hline Sheep 2623 & 7 days & $0.075 \mathrm{gm}$. & 27 days & 30 days & $0 \cdot 013 \mathrm{gm}$ & - & 一 & - & - & - & $\begin{array}{l}\text { Died (Intoxication) } 1 \text { day after } \\
\text { treatment. }\end{array}$ \\
\hline Sheep 2775 & 5 days & $0.075 \mathrm{gm}$. & - & 1 day & $0.005 \mathrm{~g} \mathrm{n}$ & - & 1 shfep & 40 c.c. & $2 \frac{1}{2} \mathrm{mtbs}$. & 一 & $\begin{array}{l}\text { Died (Gastro-Enteritis) } 9 \text { months } \\
\text { after treatment. }\end{array}$ \\
\hline Sh.ep 2776 & 11 days & $0 \cdot 07 \tilde{\mathrm{gm}}$. & - & 1 day & $0 \cdot 005 \mathrm{~g} \mathbf{n}$ & - & - & - & - & 一 & $\begin{array}{l}\text { Died (Toxaemia) } 14 \text { montins after } \\
\text { treatment. }\end{array}$ \\
\hline Sheep 1295 & 6 days & $0.06 \mathrm{gm}$. & - & 15 days & $0.01 \mathrm{gm}$. & - & - & - & - & - & $\begin{array}{l}\text { Died (Intoxication) } 1 \text { day after } \\
\text { treatment. }\end{array}$ \\
\hline Sheep 2133 & 2 days & $0.06 \mathrm{gm}$. & 21 days & 21 days & $0.01 \mathrm{gm}$ & 20 days & 1 sheep & 20 c.c. & 20 days & $\dagger$ & $\begin{array}{l}\text { Died (Gastro-enteritis) } 21 \text { days after } \\
\text { treatment. }\end{array}$ \\
\hline Sheep 2257 & 4 days & $0.06 \mathrm{gm}$. & 21 days & 21 days & $0.01 \mathrm{gm}$. & - & - & - & - & - & $\begin{array}{l}\text { Dif } d \text { (Trypanosomiasis) } 12 \text { days after } \\
\text { treatment. }\end{array}$ \\
\hline Sheep 2610 & 8 days & $0 \cdot 062 \mathrm{gm}$. & 22 days & 22 days & $0.01 \mathrm{gm}$ & - & - & - & - & 一 & $\begin{array}{l}\text { Died (Gastro-enteritis) } 15 \text { days after } \\
\text { treatment. }\end{array}$ \\
\hline Sheep 2643 & 3 days & $0.06 \mathrm{gm}$. & 15 days & 15 days & $0 \cdot 01 \mathrm{gm}$. & 20 days & 一 & 一 & - & & $\begin{array}{l}\text { Died (Trypanosomiasis) } 20 \text { days after } \\
\text { treatment. }\end{array}$ \\
\hline Sheep $21 \pm 6$ & 3 days & $0 \cdot 0616 \mathrm{gm}$. & 21 days & 21 days & $0 \cdot 01 \mathrm{gm}$ & 13 days & - & - & - & - & Subjected to further treatment. \\
\hline Sheep 2262 & 3 days & $0.057 \mathrm{gm}$ & 21 days & 21 days & $0.009 \mathrm{gm}$ & 13 days & - & - & -- & - & do. \\
\hline Sheep 2136 & 2 days & $0.067 \mathrm{gm}$. & 21 days & 21 days & $0.01 \mathrm{gm}$ & 29 days & 一 & - & - & 一 & do. \\
\hline Sheep 2137 & 3 days & $0 \cdot 07 \mathrm{gm}$. & 21 days & 21 days & $0 \cdot 01 \mathrm{gm}$. & 29 days & 一 & - & - & - & do. \\
\hline Sheep 2641 & 7 days & $0.06 \mathrm{gm}$. & 17 days & 22 days & $0.01 \mathrm{gm}$. & 29 days & - & 一 & 一 & - & do. \\
\hline
\end{tabular}


(b) One injection of Arsenophenylglycin, followed by successive doses of Novoflavin.

\section{(See Table V.)}

Five of the sheep given in Table IV. were given a second dose of Novoflavin, and in one case a third injection of this drug was given.

In two cases the animal died shortly after the second injection, and the effect on the trypanosomes could not be determined; in two cases a relapse was recorded, the trypanosomes re-appearing in the peripheral circulation, one month and three and a half months respectively, after the injection of Novoflavin.

In one of the latter two cases, a third injection of Novoflavin was given, but the animal died from general debility 21 days later, and the result could not be observed.

Only in one case was a farourable result recorded; the sheep survived for a year after the second dose of Novoflavin, and no signs of a relapse were detected.

Unfortunately the experiment as a whole is not at all conclusive. 
Table V.-Arsenophenylglycin, and successive doses of Novoflavin.

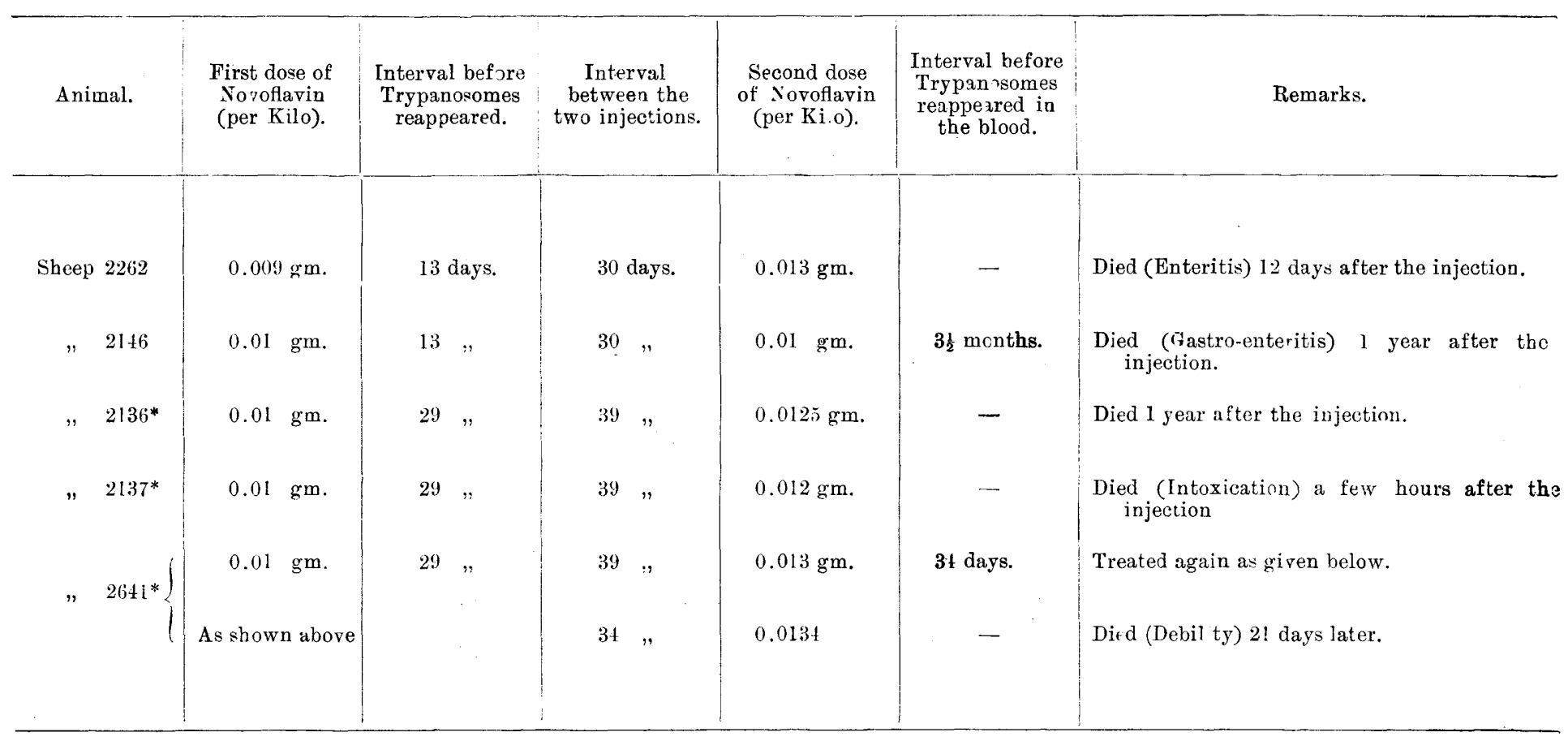

* These animals received one injection of Salvar-an, in the interval between the first and second doses of Novoflavin. 
(c) Arsenophenylglycin and Novoflavin-simultaneously.

Only three animals were treated by this method, and the results are inconclusive.

The details of the cases are as follows :-

Horse 4,018. (See Table I.)

Relapse after treatment with Arsenophenylglycin. Injected intravenously, 7 days after the trypanosomes reappeared, with 0.05 gm. Arsenophenylglycin $+0.005 \mathrm{gm}$. Novoflavin, per kilo. The trypanosomes disappeared from the blood, and were not again recorded, but the horse died 52 days after injection, from general debility and emaciation.

Sheep 2,650.

No preliminary treatment.

The sheep received, 17 days after trypanosomes appeared in the peripheral blood, $0.05 \mathrm{gm}$. arsenophenylglycin $+0.005 \mathrm{gm}$. Novoflavin per kilo.

The trypanosomes disappeared, and were not again recorded.

Death occurred 12 days later from pneumonia.

Sheep 2,622.

No preliminary treatment.

The sheep received, 23 days after trypanosomes appeared in the blood, $0.05 \mathrm{gm}$. arsenophnylglycin $+0.005 \mathrm{gm}$. Novoflavin per kilo.

The trypanosomes disappeared, and were not again recorded. Abomasum).

Death occurred after 4 days from Peritonitis (Rupture of the

\section{ARSENOPHENYLGLYCIN, TRYPANBLUE AND SODIUM ARSENITE.}

Three sheep were injected with the three drugs, given simultaneously, 15 days after trypanosomes were first seen in the peripheral blood.

The drugs were injected, as $1 \%$ solutions, in the following doses:

Arsenophenylglycin, $0.07 \mathrm{gm}$. per kilo, body weight.

Trypanblue, $0.025 \mathrm{gm}$. per kilo, body weight.

Sodium Arsenite, $0.001 \mathrm{gm}$. per kilo, body weight.

Unfortunately the doses proved to be excessive, and the animals succumbed in 1 day, 4 days, and 11 days, respectively.

3. ARSENOPHENYLGLYCIN, TRYPANBLUE, AND TARTAR EMETIC.

A. Sheep were injected (intrajugular) with :-

$0.06 \mathrm{gm}$. arsenophenylglycin per kilo-in 1-100 solution;

$0.02 \mathrm{gm}$. trypanblue per kilo-in 1-200 solution; and

$0.01 \mathrm{gm}$. tartar emetic per kilo-in 1-500 solution. 
At first the three injections were given on successive days, but such treatment proved to be too severe, and intervals of 2 days were observed later.

After 8 days, the treatment was recommenced, the doses being:-

$0.05 \mathrm{gm}$. arsenophenylglycin per kilo-in 1-100 solution.

$0.02 \mathrm{gm}$. trypanblue per kilo-in 1-200 solution.

$0.01 \mathrm{gm}$. tartar emetic per kilo--in 1-500 solution.

Sheep $3, \%$ r 1 .

Treatment started 4 days after the trypanosomes first appeared in the blood.

Trypanosomes disappeared after the first injection (arsenophenylglycin) and did not re-appear.

Sheep died-intoxication-3 days after the second dose of arsenophenylglycin.

Sheep 3,760. b]ood.

Treatment started 4 days after trypanosomes appeared in the

Trypanosomes disappeared after first injection of tartar emetic, and did not re-appear. was given.

Sheep died-Intoxication-the day the second dose of trypanblue Sheep 3,7\%4. blood.

Treatment started 6 days after trypanosomes appeared in the

Trypanosomes disappeared on the first day of the treatment, reappeared on the fourth day, and then disappeared, under the influence of the tartar emetic; no relapse was seen. Death occurred 5 days after the first course of treatment concluded, from Intoxication.

Sheep 3,454 .

Control-died from Trypanosomiasis after 6 weeks.

Result.- The above doses are evidently excessive.

N.B.-The maximal therapeutic dose of Tartar Emetic for sheep was found by experiment to be $0.01 \mathrm{gm}$. per kilogramme of body weight.

B.--Sheep were injected as follows:-

1st treatment

$0 \cdot 06 \mathrm{gm}$. arsenophenylglycin (1-100) per kilo)

$0 \cdot 02 \mathrm{gm}$. trypanblue

$0 \cdot 01 \mathrm{gm}$. emetic

(1-200) per kilo

With intervals of

$(1-500)$ per kilo two days.

and 12 days later

0.04 gm. arsenophenylglycin (1-100) per kilo

$0.01 \mathrm{gm}$. trypanblue

$0 \cdot 008 \mathrm{gm}$. emetic

(1-200) per kilo

With intervals of two days. 
In the three animals mentioned below Trypanosomes appeared in the blood three or four days previous to the commencement of treatment.

Sheep 3,972 .

The trypanosomes disappeared from the blood after the first injection, and no relapse has been found up to the present date.

The animal is still living (4th August, 1912), 5 months after the treatment.

Sheep $3, \% 61$.

The trypanosomes disappeared after the first injection; no relapse until death occurred, 6 days after the second course of treatment, from Intoxication.

Sheep 3, \%ั0.

The trypanosomes disappeared after the first injection, and did not re-appear.

The sheep died, 3 days after the second course, from Enteritis.

Sheep 3,\%63.

Control-died from Trypanosomiasis after 5 weeks.

The result in one out of three sheep is apparently very satisfactory, but the above doses were obviously proving very severe.

C.--Sheep received the following intrajugular injections:-

$0.06 \mathrm{gm}$. arsenophenylglycin (1-100) per kilo

$0.02 \mathrm{gm}$. trypanblue (1-200) per kilo

$0.01 \mathrm{gm}$. emetic

(1-500) per kilo $\}\}$ of two days.

and 8 days later
$0.05 \mathrm{gm}$. arsenophenylglycin
$0.02 \mathrm{gm}$. trypanblue
$0.007 \mathrm{gm}$. emetic
(1-100) per kilo
(1-200) per kilo With intervals (1-500) per kilo. $\}$ of two days.

S7eep 3,762.

Treatment commenced 3 days after trypanosomes were first seen in the blood.

The trypanosomes disappeared after the first injection, and were not again seen, although after death, which occurred 70 days after the conclusion of the second course of treatment, the lesions presented were those of Trypanosomiasis.

Sheep 3,758 .

Treated three days after trypanosomes were first seen in the blood. The trypanosomes disappeared after the first injection, and re-appeared for one day only, six days after the second treatment concluded. Death occurred ten days after the second treatment, from Chronic Intoxication. 
Kemarks.-The treatment was still too severe, although in one (out of two cases) a relapse appears to have occurred.

D.--Sheep were injected with the following :-

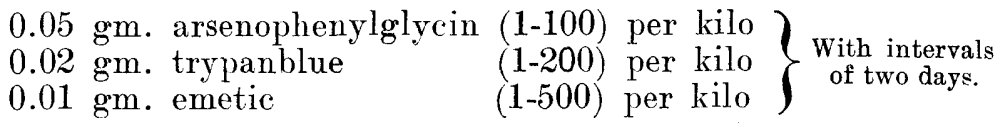

and 12 days later,
$\begin{array}{lll}0.01 & \mathrm{gm} . & \text { trypanblue } \\ 0.04 & (1-200) & \text { per kilo } \\ \text { gm. arsenophenylglycin }(1-100) & \text { per kilo }\end{array}$
$0.008 \mathrm{gim}$. emetic
$(1-100)$
$(1-500)$
per kilo
$\left\{\begin{array}{c}\text { With intervals } \\ \text { of two days. }\end{array}\right.$

N.B.-The undermentioned sheep had previously been treated unsuccessfully with Salvarsan.

Sheep 3,\%66.

Treated 13 days after trypanosomes were first seen in the blood.

The trypanosomes disappeared after the first injection, and reappeared, for one day only, on the ninth day after the injection of emetic. The animal was too weak to permit the carrying out of the second course of injections.

Death occurred, 15 days after the first course, from Intoxication.

Sheep 3,473.

Treated 15 days after trypanosomes were first seen in the blood. The trypanosomes disappeared after the first injection, and reappeared 8 days after the second course of treatment concluded.

Death occurred, 46 days after the second course, from Trypanosomiasis.

Sheep 3,756.

Control (also relapsed after Salvarsan treatment).

Died from Trypanosomiasis, 76 days after inoculation.

Remarks.--The treatment was too severe, but insufficient to cure completely those animals which did not succumb to the effects of the trypanocidal agents injected.

E.-The doses were reduced to the following :-
$0.04 \mathrm{gm}$. arsenophenylglycin
$0.01 \mathrm{gm}$. trypanblue
$0.008 \mathrm{gm}$. emetic
$\left.\begin{array}{ll}(1-100) & \text { per kilo } \\ (1-200) & \text { per kilo } \\ (1-500) & \text { per kilo }\end{array}\right\} \begin{gathered}\text { Intrajugular, } \\ \text { with intervals } \\ \text { of two days. }\end{gathered}$

and, after 11 days,
$0.05 \mathrm{gm}$. arsenophenylglycin
$(1-100)$ per kilo
$(1-500)$ per kilo
$\left\{\begin{array}{c}\text { Half intrajugular } \\ \text { and half given } \\ \text { subcutaneously, } \\ \text { with an interval } \\ \text { of three days. }\end{array}\right.$

*rThese two sheep had previously been treated unsuccessfully with Salvarsan. 
* Sheep 3,810.

Treated 14 days after trypanosomes were first seen in the blood. The trypanosomes disappeared from the peripheral blood after the first injection, and re-appeared (in small numbers) 3 days later.

They disappeared after the injection of emetic, re-appearing on the third day, for one day only. Five days later they were again recorded, and persisted for three days, until the second course of injections was commenced.

No relapse was observed.

Death occurred, 35 days after the second treatment, from Peritonitis.

* Sheep 3,813.

Treated 14 days after the trypanosomes were first seen in the blood. The trypanosomes disappeared after the first injection, reappeared ten days after the emetic injection, and on the following day disappeared again, under the influence of the second injection of arsenophenylglycin.

The animal is still alive (4th August, 1912) and no relapse has been noted to date (128 days after the second course concluded).

Sheep 3,819.

Treated 22 days after trypanosomes were first seen in the blood. No second course of injections was given.

The trypanosomes disappeared after the first injection, and no relapse has been observed up to the present date.

The animal is apparently in excellent health at the present date (4th August, 1912), 133 days after the conclusion of the treatment.

Sheep 3,759. blood.

Treated 38 days after the appearance of trypanosomes in the

Only one course of three injections was given.

The trypanosomes disappeared from the peripheral blood after the first injection of arsenophenylglycin, and were not again recorded. The animal is still alive (4th August, 1912), 132 days after the suspension of treatment.

Sheep 3,765.

Treated 37 days after the appearance of trypanosomes in the blood. Only the first course of injections was given.

The trypanosomes disappeared after the first injection, and were not again recorded.

The sheep is still alive, 132 days after the suspension of treatment.

Remarks.--In three cases the first course of injections has apparently proved successful, no relapses being recorded up to the present time, more than four months after the termination of the treatment. 
In two cases this first course of injections proved insufficient, and a second course of the injections was given; this appears to have succeeded in both cases, although in one case death occurred 35 days later, from an accidental complication.

The later history of the four sheep, which have survived until the present date, will be of considerable interest, and the experiment cannot yet be considered to have terminated.

\section{Arsenopimnylglycin and Tartar Emetic.}

A.- Sheep were injected intravenously with:-

One does of $0.05 \mathrm{gm}$. Arsenophenylglycin (1-100) per kilo, and 3 successive doses of $0.005 \mathrm{gm}$. Emetic (1-500) per kilo, with intervals of two days between the injections.

Four sheep were subjected to the above treatment, and in each case the treatment was too severe, the animal succumbing 1-3 days after the third injection of emetic was given.

B.-Alternate injections of $0.05 \mathrm{gm}$. arsenophenylglycin (1-100) per kilo and $0.01 \mathrm{gm}$. emetic (1-500) per kilo

At first the injections were made at intervals of 2 or 3 days $(a)$, but later the interval was increased to four days $(b)$.

In all the cases mentioned below, treatment was commenced 3-5 days after trypanosomes were first seen in the blood.

Sheep 3,8\%1.

Four injections $(a)$. Trypanosomes re-appeared in the blood 14 days after the last injection. Other treatment was then instituted.

Sheep 3,8\%3.

Two injections $(a)$. Trypanosomes re-appeared in the blood 10 days after the last injection. The sheep died from Trypanosomiasis, 12 days after the second (emetic) injection.

Sheep 3,879.

Four injections (a) followed in 9 days by two injections $(b)$. Trypanosomes were seen in the blood, for one day, 3 days after the third injection of arsenophenylglycin, and they re-appeared 8 days after the third dose of emetic. Other treatment was then instituted.

Sheep $3,87 \%$.

Two injections (a), followed in 13 days by two injections $(b)$.

Relapses occurred 10 days after the first dose, and 8 days after the second dose, of emetic. Further treatment was then commenced.

Sheep 3,872.

Two injections (a), followed in 13 days by two injections (b).

Relapses occurred 10 days after the first injection of emetic, and 8 days after the second dose. Other treatment was then commenced. 
Sheep 3,866.

Four injections (a), followed in 9 days by two injections $(b)$. Trypanosomes re-appeared in the blood, for one day, 7 days after the second injection of emetic, and for one day on the 8th day after the third dose of emetic.

(Other treatment was then instituted.

Thus six sheep were treated by this method, the number of injections made varying in different cases from two to six.

Relapses occurred in every case, the trypanosomes re-appearing. in the peripheral blood from $\gamma$ to 14 days after the injection of the emetic. It is evident that this treatment is not at all effective, and that the interval between the injection and the relapse was becoming distinctly shorter, when several injections were given.

C.--Treatment consisted in injecting into the jugular vein:-$\left.\begin{array}{cc}0.04 \mathrm{gm} \text {. Arsenophenylglycin } \\ \text { and } \\ 0.005 \mathrm{gm} . \text { emetic } & (1-500) \text { per kilo }\end{array}\right\} \begin{gathered}\text { Given } \\ \text { simultaneously. }\end{gathered}$

The injection (of the same quantities) was repeated at intervals varying in the different cases.

The following sheep were treated by this method, treatment being commenced 3 to 5 days after trypanosomes were first seen in the peripheral blood.

Sheep 3,801.

1st injection.-Relapse not seen.

2nd injection, 5 days later-Relapse in 12 days.

3rd injection, 15 days later-Relapse in 10 days.

4th injection-15 days later-Relapse in 10 days.

Died (Trypanosomiasis) - 15 days after the 4 th injection.

Sheep 3,802.

1st injection-Relapse not seen.

2nd injection-5 days later-Relapse after 8 days.

3rd injection-11 days later-Relapse after 8 days.

4th injection-19 days later-Relapse after 10 days

Other treatment was then instituted.

Sheep 3,803.

1st injection-Relapse after 9 days.

2nd injection-9 davs later-Relapse after 6 days.

3rd injection-7 days later-Relapse after 1 day, 3 days, etc.

Died (Trypanosomiasis) -18 days after the third injection.

Sheep 3,804.

1st injection-Relapse after 8 days.

2nd injection-9 days later-Relapse after 15 days.

3rd injection-26 days later-Relapse after 10 days.

Other treatment was then instituted. 
Sheep 3,805.

1st injection-Relapse after 8 days.

2nd injection-after 9 days-Relapse after 6 days.

3rd injection-after 7 days-Relapse after 10 days.

4th injection-after 19 days-Relapse after 10 days.

Other treatment was then instituted.

Sheep 3,782.

1st injection- No relapse seen.

2nd injection-after 5 days-Relapse after 9 days.

3rd injection-after 11 days-Relapse on 1st and 5th days, etc.

4th injection-after 19 days-Relapse after 10 days.

Died (Trypanosomiasis) - 18 days after the fourth injection.

Three sheep, which had previously been treated unsuccessfully with alternate doses of these two agents (treatment $4 \mathrm{~B}$ ), were given one simultaneous injection of the doses mentioned above.

In each case trypanosomes reappeared in the peripheral blood ten days after the injection.

The method is evidently not effective, or the doses given are insufficient, for in every case injection was followed by relapse, usually in 8 or 9 days.

It is significant that on two occasions the relapse occurred only one day after the third injection.

It is doubtful whether the doses could be increased by more than a very small amount.

\section{Combined Treatment with Quinine and Atoxyl.}

This experiment was suggested by the publication of Dr. Helm "Heilung von Trypanosomiasis in zwei Fällen" (Archiv für Schiffsund Tropen-Hygiene, 1911).

Six sheep, infected with the "Guara-Guara" strain of trypanosome, were treated as follows :-

Two doses of 2 grammes of Quinine Hydrochloride were administered per os. with an interval of three days, 3 grammes of atoxyl (in a 1-50 solution) was injected into the jugular vein, on the day following that on which the second dose of quinine was given.

In one case this treatment was recommenced, ten days after the injection of atoxyl.

Each of the sheep used in this experiment weighed approximately 34 kilogrammes.

It will be seen, by reference to Table VI., that we did not by any means get the satisfactory results obtained in two cases by Dr. Helm.

In two of our cases the animal died shortly after the injection of atoxyl, and the dose (approximately $0.088 \mathrm{gm}$. per kilo.) could not, therefore, be increased with safety.

In two sheep the trypanosomes in the peripheral blood diminished in number, but never actually disappeared.

In the remaining two animals, both of which had previously been treated with Salvarsan, the trypanosomes disappeared for a short period (two and four days respectively), and then increased rapidly in numbers. 
Table VI.-Treatment with Quinine axd Atoxyl.

\begin{tabular}{|c|c|c|c|}
\hline Animal. & $\begin{array}{l}\text { Interval between the } \\
\text { appearance of } \\
\text { trypanosomes in the } \\
\text { blood and treatment. }\end{array}$ & $\begin{array}{c}\text { Effect of the treatment of the trypanosomes } \\
\text { in the peripheral blood. }\end{array}$ & Remarks. \\
\hline Sheep 3817 & 4 days. & Trypanosomes diminished for 5 days after the & D:ed (trypanozomiasis) 7 days after the atoxyl \\
\hline Sheep 3816 & 4 days. & $\begin{array}{l}\text { Trypanosomes diminished for } 4 \text { days after the } \\
\text { injection of atoxyl. }\end{array}$ & $\begin{array}{l}\text { Died (trypanosomiasis) } 7 \text { dass after the atoxyl } \\
\text { was given. }\end{array}$ \\
\hline Sheep 3815 & 4 days. & $\begin{array}{l}\text { Trypanosomes disappeared after the injection } \\
\text { of atoxyl. }\end{array}$ & $\begin{array}{l}\text { Died (intoxication) } 1 \text { day after the atoxyl was } \\
\text { given. }\end{array}$ \\
\hline Sheep 3818 & 3 days. & $"$ & $"$ \\
\hline * Sheep 3768 & $13 \mathrm{dars}$ & $\begin{array}{l}\text { Trypancsomes disappeared for } 2 \text { days after } \\
\text { atoxyl was given. }\end{array}$ & $\begin{array}{l}\text { Died (trypanosomiasis and enteritis) } 10 \text { days } \\
\text { after the atoxyl was given, }\end{array}$ \\
\hline Sheep 3755 & Control. & $\begin{array}{l}\text { Trypanosomes disappeared for } 1 \text { days after } \\
\text { atoxyl was given. }\end{array}$ & $\begin{array}{l}\text { Died (trypmosomiasis and enteritis) } 11 \text { days } \\
\text { after the atoxyl was given and } 1 \text { day atter } \\
\text { the first dose of quinine in the second } \\
\text { course. } \\
\text { Di. d (trypanosomiasis) in } 9 \text { days. }\end{array}$ \\
\hline
\end{tabular}

* Previously treated unsuccessfully with salvarsan. 